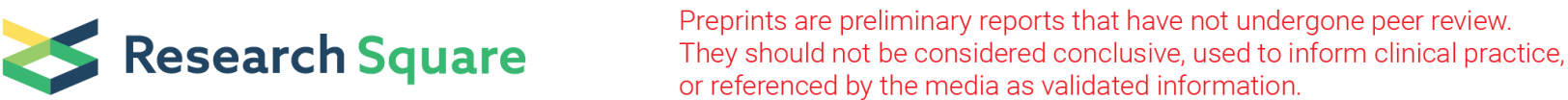

\section{Study On The Implementation Status and Countermeasures of The Standardized Resident Training System in China}

\section{Zixin Li}

Weifang Medical University

Songyi Liu

Weifang Medical University

Wenqi Meng

Weifang Medical University - Fuyanshan Campus: Weifang Medical University

Xiaoli Jiang

Weifang Medical University

Haibo Peng

Weifang Medical University

Qianqian Yu ( $\nabla$ yqq_7921@163.com )

Weifang Medical University https://orcid.org/0000-0001-8439-4366

Wenqiang Yin

Weifang Medical University

Zhongming Chen

Weifang Medical University

Dongping Ma

Weifang Medical University

Junwei Song

Weifang hospital of traditional Chinese medicine

Research

Keywords: the standardized resident training system, Satisfaction, Countermeasures

Posted Date: November 11th, 2021

DOI: https://doi.org/10.21203/rs.3.rs-1037709/v1

License: (c) (i) This work is licensed under a Creative Commons Attribution 4.0 International License.

Read Full License 


\section{Abstract \\ Object:}

By combing the policy content of the standardized resident training system in China, this paper analyzes the residents' cognition and satisfaction evaluation of standardized training policy, and discusses the implementation obstacles and feasible strategies of the Chinese standardized resident training.

\section{Method}

Using policy text analysis to sort out the policy content of the Chinese standardized resident training system; A questionnaire survey was conducted among 1048 residents in 5 standardized training bases for residents in Shandong Province, China, and a qualitative interview was conducted with 42 residents by personal in-depth interview. Descriptive analysis and binary logistic regression model were used to statistically analyze the residents' cognition of the training policy, the way of participating in the training, the harvest during the training, existing problems, satisfaction evaluation, and to explore the implementation obstacle factors and optimization strategies of the standardized resident training policy in China.

\section{Result}

Through quantitative investigation and qualitative interview, it is found that the standardized resident training has improved the students' clinical theoretical knowledge level, practical ability, and doctorpatient communication ability. However, there are still some problems in the standardized resident training in China, such as unreasonable time arrangement, low salary and living security level of residents, weak awareness of teaching, inadequate implementation of training content and assessment, etc.

\section{Conclusion}

The implementation of the standardized resident training system in China has played an important role in cultivating homogeneous and qualified doctors and improving the ability and level of doctors. However, the survey found that the training arrangement is unreasonable, the salary and living security level is not high, and put forward that the training time should be arranged reasonably, the salary and treatment level should be improved, and the awareness of teachers' responsibility should be improved Strengthen the implementation of training content and assessment. This paper can provide a reference for graduate medical education and the training of human resources in healthcare in other countries and regions.

\section{Background}


Standardized resident training refers to the systematic and standardized training imparted to medical graduates. This training is aimed at improving their clinical proficiency and is conducted in recognized training bases after the residents complete their medical graduate programs. The purpose of this system is to produce qualified doctors who can provide similar high standards of care [1]. The implementation of the standardized resident training system is concurrent with the growth of medical and health services and the growth of clinical medical talents. It is an important measure for establishing a long-term system for training medical personnel, strengthening the pool of medical and health personnel, and ensuring optimal and sustainable development of healthcare undertakings.

In the mid-19th century, Professor Langenbeck from the Berlin University in Germany first proposed the idea of establishing a resident system [2-3]. In 1876, in order to train surgeons, Dr. Horst - the director of surgery at Johns Hopkins Hospital - established the American resident system. In the 1920s, the standardization of the resident training system, largely aimed at the development of core competence, became an important part of medical education in the United States [4-5]. In 1929, the Royal College of Physicians and Surgeons of Canada was established and began to train residents [6]. In 1993, the CanMEDS system that highlighted the roles and responsibilities of family physicians - including Medical Expert, Communicator, Collaborator, Manager, Health Advocate, Scholar, and Professional along with seven core competencies - was proposed [7]. Subsequently, this system developed further to form a more mature, competency-oriented resident training system [8]. In 1948, the United Kingdom started standardized resident training [9], and in 2005, the Modern Medical Career program that emphasized the establishment of competency- and workplace-based assessment of resident training was promoted [10$11]$.

France, Japan, Australia, and other developed countries have also established systematic standardized resident training systems according to local conditions. They have systematic regulations for key aspects of resident training, such as training institutions, training standards, quality control, and qualification recognition, all of which allow standardized, institutionalized, and legalized management [12-19]. Currently, the "government leading, industry participating in management, and medical institutions responsible for implementation" model is common in several countries. The government is responsible for providing training funds and designing the training system, and the industry is responsible for identifying training bases and establishing training objectives, in order to ensure training quality [20].

The standardized resident training system in China has undergone three phases: spontaneity, conscious decision-making, and national will. The first phase occurred between 1921 and 1993. The rudimentary form of the Chinese standardized resident training system can be traced back to the "24-hour responsibility system for chief residents and residents" policy implemented by Peking Union Medical College in 1921. At that time, there was no unified standard or norm of care. The second phase of conscious decision-making persisted from 1993 to 2013. In 1993, the former Ministry of Health issued the "Trial Measures for Standardized Training of Clinical Residents" and "Trial Outline for Standardized Training of Clinical Residents," which were explored and trialed at all levels. Some regions began to explore the " $3+X$ " model, that is, on the basis of three-year standardized resident training, 2-4 years 
standardized specialist training was carried out according to the training standards and requirements of each specialist. Finally, the third phase, referred to as the national will stage, commenced in 2013 and persists to date. The "Opinions of the State Council of the CPC Central Committee on Deepening the Reform of the Medical and Health System" issued by the CPC Central Committee and the State Council in 2009 clearly highlight the need for "establishing a standardized resident training system and strengthening the continuing medical education" [21]. To further reform China's medical and health system and medical education program, in 2013, seven ministries and commissions of the State Council jointly issued the "Guidance on Establishing a Standardized Resident Training System" and emphasized the connection between professional medical education and standardized resident training [22]. This marked the formal establishment and implementation of the standardized resident training system in China, as well as the establishment of a medical personnel training system that was suited to meet national healthcare requirements.

It is expected that standardized resident training will become a key factor and breakthrough in the journey towards promoting new healthcare reforms in China. The government is trying to meet international standards through a standardized reform of resident training, to improve the level of healthcare in China's medical institutions, narrow the gap between different medical institutions, and achieve equalization of public health services.

After the promulgation of the "Guidance on Establishing a Standardized Resident Training System," the National Health and Family Planning Commission successively issued a series of supporting documents, such as "Methods for the Management of Standardized Resident Training (trial)" [23], "Standard for Accreditation of Standardized Resident Training Bases (Trial)" [24], "Contents and Standards of Standardized Resident Training (Trial)" [25], "Implementation Methods of Recruitment for Standardized Resident Training" [26], and the "Implementation Methods of Standardized Resident Training Assessment" [27]. Through these, the policy system for standardized resident training was first constructed. All provinces (autonomous regions and municipalities directly under the central government) were required to fully switch to standardized resident training by 2015 and completely establish the standardized resident training system by 2020. All clinicians with a bachelor's degree or higher who took on medical practice positions for the first time were required to receive standardized resident training.

\section{Main Features of the Standardized Resident Training Policy in China}

According to the relevant policies of the standardized resident training system in China [22-27], the following were to be monitored and established: funding, recruitment, training bases, training curriculum, training assessment, and management and treatment of trainees.

\section{Funding guarantees}

The standardized resident training system in China is supported by a multi-input mode of funding, which includes government investment, self-financing, and social support. Central finance grants provide a one- 
time subsidy of RMB 5 million per training base for the purchase of equipment for residents at the standardized training base. Each resident receives a subsidy of RMB 30000 per year.

\section{Recruitment}

Recruitment targets include those who intend to be involved in medical practice at medical colleges and universities (including clinical medicine, stomatology, traditional Chinese medicine, and integrated traditional Chinese and western medicine). This spectrum includes graduates with a bachelor's degree or above; personnel who have engaged in medical work, qualified to be medical practitioners, and need to receive training; and other personnel who require training.

\section{Training bases}

Standardized training for residents can be held at training bases and professional bases. Training bases are medical and health institutions where standardized training of residents is undertaken, and these are composed of qualified professional bases. Professional bases are led by qualified professional departments. At professional bases, the relevant departments coordinate and jointly complete training tasks. Training bases are required to meet a few basic criteria, including hospital accreditation, appropriate training facilities and equipment, and an established training system. The training bases are required to meet the basic requirements of teaching staff, department construction and training plan setting. There are 34 specialties in standardized resident training, such as internal medicine, pediatrics, emergency department, dermatology, etc.

\section{Training curriculum}

The core of standardized resident training is to competency cultivation. According to the guidelines of standardized resident training, training in different areas, including medical ethics, policies and regulations, clinical practice, medical theory, and interpersonal communication, is imparted. The focus is on improving the ability of clinicians to perform standardized diagnosis and treatment, while giving due consideration to medical teaching and awareness of scientific research.

\section{Training assessment}

Training assessment includes process assessment and graduation assessment. Process assessment involves daily assessment, departmental assessment, and annual assessment of medical ethics, clinical professionalism, attendance, and clinical practice skills. Graduation assessment is divided into two parts. Residents who have obtained the Doctor Qualification Certificate and passed the training process assessment can apply for the graduation assessment. Those who pass standardized resident training are issued a combined certificate of qualification for the standardized resident training.

\section{Management and treatment of trainees}


During the training period, the original personnel (staff) and salary agreements of the trainees appointed by the unit remain unchanged; the appointed unit, training base, and trainees sign a training agreement; and the difference between the salary paid by the appointed unit and the salary of residents working under the same conditions is paid out by the training base. The trainees sign training agreements with the training base, and their living allowances during the training period are paid by the training base. The allowance standards are determined based on the salary received by residents working under the same conditions at the training base. The trainees who are postgraduates are required to meet the relevant state provisions on postgraduate education, and the training base may grant them appropriate living allowances according to the training assessment.

\section{Object And Method}

\section{Respondents and tools}

According to the type and scale of standardized resident training hospitals, the principle of stratified random sampling was adopted to select 5 standardized resident training bases in Shandong Province, and 1060 residents were selected for standardized training. The questionnaire on students' cognitive evaluation of participating in standardized resident training prepared by the research group was used as a measurement tool for quantitative investigation, the main contents of the questionnaire include personal basic information, cognition of standardized resident training, evaluation of standardized resident training and satisfaction with standardized resident training. Finally, 1048 valid questionnaires were collected, and the effective recovery rate was $98.9 \%$.

According to the principle of information saturation, the qualitative interview uses the method of personal in-depth interview to collect data. Through interviewing 42 residents, we can understand the problems existing in the implementation of standardized resident training. The core contents of the interview include: (1) the basic situation of residents (gender, age, training time, Department, monthly average training subsidy, etc.), (2) During your participation in the standardized resident training, what did you do not meet your expectations and requirements? (3) What benefits and disadvantages do you think the current standardized resident training has for you? (4) Combined with the actual training, how do you think the standardized resident training policy can be improved? In a quiet and undisturbed environment, the researcher first introduces his identity, research project, interview purpose and interview content, and ensures the confidentiality of the interview content. After obtaining the consent of the interviewee, the interview starts and records. The interview time is $20-30 \mathrm{~min}$. The specific time varies according to the wishes of the interviewers. Finally, the recording code is given and the recording is stopped.

\section{Analysis method}

In the quantitative study, SPSS software was used for data entry and statistical processing. The data were analyzed by simple rate, constituent ratio and binary logistic regression. The difference was statistically significant $(P<0.05)$. In the qualitative research, two researchers are independently responsible for recording, transcribing, and checking the text data. According to the interview outline 
design, the data are classified and extracted according to the theme synthesis method, the similar and related topics are summarized into one category, and the results of qualitative analysis are displayed by using fish bone diagram and other methods.

\section{Result}

\section{Basic information of respondents}

A total of 1048 trainees were investigated, most of them were women (61.2\%) and less were men (37.9\%); $89 \%$ were aged 30 years and below, with an average age of $27.01 \pm 2.663$ years; The marriage situation was mainly unmarried, accounting for $68.3 \% ; 99.2 \%$ of the students have the highest degree of Bachelor degree or above, and only $0.2 \%$ of the trainees have the lowest degree of college; The average monthly living and training subsidy is less than RMB 1000 , accounting for $53.3 \%$; The monthly average living and training subsidy of RMB 5000 or above is the lowest, accounting for $0.8 \% .63 .9 \%$ obtained the qualification certificate of practicing assistant doctor or practicing doctor, and $35.6 \%$ did not obtain any qualification certificate. Most of the reasons for choosing this training base are the fame of the hospital, accounting for $40.1 \%$; others recommended at least $5.1 \%$. Table 1 shows the detailed results. 
Table 1

Basic information of trainees

\begin{tabular}{|c|c|c|c|}
\hline Variable & Category & Number & $\begin{array}{l}\text { Proportion } \\
\text { (\%) }\end{array}$ \\
\hline \multirow[t]{2}{*}{ Gender } & Male & 397 & 37.9 \\
\hline & Female & 641 & 61.2 \\
\hline \multirow[t]{4}{*}{ Age } & 25 and under & 359 & 34.3 \\
\hline & $26-30$ & 583 & 55.6 \\
\hline & $31-35$ & 102 & 9.7 \\
\hline & 36 and over & 4 & 0.4 \\
\hline \multirow[t]{6}{*}{ Average monthly subsidy (RMB) } & Less than 1000 & 558 & 53.3 \\
\hline & $1000-2000$ & 232 & 22.1 \\
\hline & $2000-3000$ & 188 & 17.9 \\
\hline & $3000-4000$ & 23 & 2.2 \\
\hline & $4000-5000$ & 39 & 3.7 \\
\hline & 5000 and above & 8 & 0.8 \\
\hline \multirow[t]{2}{*}{ Marital status } & Unmarried & 717 & 68.4 \\
\hline & Married & 331 & 31.6 \\
\hline \multirow[t]{5}{*}{ Highest education } & $\begin{array}{l}\text { Technical secondary school and } \\
\text { below }\end{array}$ & 6 & 0.6 \\
\hline & Junior college & 2 & 0.2 \\
\hline & Undergraduate & 666 & 63.5 \\
\hline & Master & 367 & 35 \\
\hline & Doctor & 7 & 0.7 \\
\hline \multirow[t]{4}{*}{ Practicing qualification certificate } & Nothing & 373 & 35.6 \\
\hline & Practicing assistant physician & 8 & 0.8 \\
\hline & Medical practitioner & 661 & 63.1 \\
\hline & Other & 6 & 0.6 \\
\hline \multirow{3}{*}{$\begin{array}{l}\text { Reasons for selecting training } \\
\text { base }\end{array}$} & Hospital fame & 420 & 40.1 \\
\hline & It's close to home & 191 & 18.2 \\
\hline & Recommended by others & 53 & 5.1 \\
\hline
\end{tabular}




\begin{tabular}{|llll|}
\hline Variable & Category & Number & $\begin{array}{l}\text { Proportion } \\
\text { (\%) }\end{array}$ \\
\hline Other & 384 & 36.6 \\
\hline
\end{tabular}

\section{Trainees' awareness of training policy}

The trainees' awareness of the three-year rotation system, the residential training policy of their hospital, the training content at each stage, the training policy and the relevant laws and regulations accounted for $57.2 \%, 50.5 \%, 48.6 \%, 46.9 \%$ and $31.0 \%$ respectively. The residents' awareness of the relevant contents of residential training is low. Table 2 shows the detailed results.

Table 2

Trainees' awareness of SRT policy

\begin{tabular}{|llllll|}
\hline Variable & $\begin{array}{l}\text { Very } \\
\text { unclear }\end{array}$ & Unclear & General & Clear & $\begin{array}{l}\text { Very } \\
\text { clear }\end{array}$ \\
\hline Three-year rotation system & $6(0.6)$ & $73(6.9)$ & $370(35.3)$ & $512(48.9)$ & $87(8.3)$ \\
\hline Hospital standardized training policy & $14(1.3)$ & $83(7.9)$ & $421(40.2)$ & $450(42.9)$ & $80(7.6)$ \\
\hline $\begin{array}{l}\text { Training details and training contents } \\
\text { of each stage }\end{array}$ & $15(1.4)$ & $92(8.8)$ & $432(41.2)$ & $446(42.6)$ & $63(6.0)$ \\
\hline Standardized resident training policy & $24(2.3)$ & $81(7.8)$ & $451(43.0)$ & $414(39.5)$ & $78(7.4)$ \\
\hline Medical related laws and regulations & $35(3.3)$ & $198(18.9)$ & $490(46.8)$ & $276(26.3)$ & $49(4.7)$ \\
\hline
\end{tabular}

\section{The ways trainees participate in the training}

The main training methods for trainees were rotation with related departments (95.2\%), department lecture (89.7\%), case discussion (82.0\%), and hospital knowledge lecture (77.3\%). Meanwhile, attending academic conference (63.9\%) was also an important training method. Table 3 shows the detailed results.

Table 3

The ways trainees participate in the training

\begin{tabular}{|lll|}
\hline Variable & Number & Proportion (\%) \\
\hline Rotation with related departments & 998 & 95.2 \\
\hline Department lecture & 940 & 89.7 \\
\hline Case discussion & 859 & 82.0 \\
\hline Hospital knowledge lecture & 810 & 77.3 \\
\hline Attending academic conference & 670 & 63.9 \\
\hline Equivalent learning & 314 & 30.0 \\
\hline Other & 33 & 3.1 \\
\hline
\end{tabular}




\section{The benefits of training}

Most of the trainees improved their clinical practice skills (90.5\%), consolidated their theoretical knowledge (84.2\%) and improved their doctor-patient communication ability (72.6\%) after attending the training. Similarly, nearly half of the trainees said they had improved their knowledge of relevant laws and regulations after attending the training (41.1\%). Table 4 shows the detailed results.

Table 4 The benefits of training for residents

\begin{tabular}{|llll|}
\hline Variable & Number & Proportion (\%) \\
\hline Improve clinical practice skills & 948 & 90.5 \\
\hline Consolidate theoretical knowledge & 882 & 84.2 \\
\hline Improve doctor-patient communication ability & 761 & 72.6 \\
\hline Understand relevant policies and regulations & 431 & 41.1 \\
\hline Else & 32 & 3.1 \\
\hline
\end{tabular}

\section{Problems during training}

$80.3 \%$ of the trainees reported that their income could not meet their daily needs during the training period. Meanwhile, accommodation and various facilities could not meet their needs (35.9\%), hospital rotation arrangement was unreasonable (31.3\%), and work load was difficult to adapt (26.2\%). Table 5 shows the detailed results.

Table 5

Problems during resident training

\begin{tabular}{|c|c|c|}
\hline Variable & Number & Proportion (\%) \\
\hline Income cannot meet daily expenses & 842 & 80.3 \\
\hline Accommodation and facilities cannot meet demand & 376 & 35.9 \\
\hline Hospital rotation arrangement is not reasonable & 328 & 31.3 \\
\hline Hard to adapt to heavy workload & 275 & 26.2 \\
\hline Else & 33 & 3.1 \\
\hline
\end{tabular}

Residents' satisfaction with various dimensions of the training process mainly includes: satisfaction with standardized training content, training methods, training schedule, training teachers, training policies, training base facilities, salary and treatment, and training effects. Among them, the highest satisfaction is teacher training $(73.6 \%)$, training base $(67.2 \%)$, training content $(64.7 \%)$, the lowest satisfaction is training 
schedule (56.8\%), training policy (52.9\%), salary and treatment (42.2\%). Table 6 shows the detailed results.

Table 6

Residents' satisfaction with each dimension of training ( $\mathrm{n}, \%)$

\begin{tabular}{|llllll|}
\hline Variable & Very satisfied & Satisfied & General & Dissatisfied & Very dissatisfied \\
\hline Training content & $184(17.6)$ & $494(47.1)$ & $300(28.6)$ & $53(5.1)$ & $17(1.6)$ \\
\hline Training methods & $181(17.3)$ & $470(44.8)$ & $324(30.9)$ & $50(4.8)$ & $23(2.2)$ \\
\hline Training time & $165(15.7)$ & $430(41.1)$ & $329(31.4)$ & $86(8.2)$ & $328(3.6)$ \\
\hline Training of teachers & $240(22.9)$ & $531(50.7)$ & $216(20.6)$ & $42(4.0)$ & $19(1.8)$ \\
\hline Training policy & $163(15.5)$ & $392(37.4)$ & $333(31.8)$ & $107(10.2)$ & $53(5.1)$ \\
\hline Training base & $205(19.6)$ & $499(47.6)$ & $271(25.9)$ & $51(4.9)$ & $22(2.0)$ \\
\hline In compensation & $200(19.1)$ & $242(23.1)$ & $210(20.0)$ & $302(28.8)$ & $150(14.6)$ \\
\hline Training effect & $153(14.6)$ & $460(43.9)$ & $346(33.0)$ & $62(5.9)$ & $27(2.6)$ \\
\hline
\end{tabular}

\section{The influencing factors on trainees' satisfaction with standardized resident training}

In this study, binary logistic regression analysis was used to analyze the factors that might affect residents' satisfaction with their training institutions. Taking overall satisfaction with training work as the dependent variable, gender, age, marital status, to the hospital rules from policy, rules' understanding of the culture content, the rotation system three years, to the necessity of standardization training for their own judgment, and the standardization training content, training methods, training schedule, training teachers, training base facilities, compensation, training effect factors as independent variables, satisfaction with the degree of binary variables were coded with 0 and 1 , and multi-classification ordered variables were coded with natural values, and binary logistic regression analysis was performed. The regression results showed that the degree of understanding of standardized training in the hospital, the judgment of the necessity of participating in standardized training, the degree of satisfaction with standardized training content, training faculty, training salary and treatment were the factors that affected the overall satisfaction of residents with the work of residential training. Table 7 shows the detailed results. 
Table 7

Logistic analysis results of trainees' satisfaction with training institutions

\begin{tabular}{|lllll|}
\hline Factor & $\boldsymbol{B}$ & $\mathbf{O R}$ & $\mathbf{9 5 \%}$ C.I. & $\boldsymbol{P}$-Value \\
\hline Sex (ref: Male) & 0.092 & 1.097 & $0.714-1.684$ & 0.673 \\
\hline Age & 0.107 & 1.113 & $0.991-1.251$ & 0.071 \\
\hline Marital status (ref: Single) & 0.145 & 1.156 & $0.62-72.134$ & 0.642 \\
\hline knowledge of the hospital's educational policy & 0.611 & 1.842 & $1.297-2.615$ & 0.001 \\
\hline Knowledge of the content of the training & 0.163 & 1.177 & $0.830-1.668$ & 0.362 \\
\hline Necessity for participate in the training & 0.333 & 1.395 & $1.081-1.800$ & 0.010 \\
\hline Knowledge of "three-year rotation system" & -0.384 & 0.681 & $0.482-0.962$ & 0.029 \\
\hline Satisfaction with training Content & 1.526 & 4.600 & $2.961-7.147$ & 0.000 \\
\hline Satisfaction with training method & 0.392 & 1.479 & $0.943-2.321$ & 0.089 \\
\hline Satisfaction with the schedule of training & 0.292 & 1.340 & $0.972-1.847$ & 0.074 \\
\hline Degree of teacher satisfaction & 0.660 & 1.935 & $1.319-2.838$ & $\mathbf{0 . 0 0 1}$ \\
\hline Satisfaction with the facilities & 0.323 & 1.381 & $0.986-1.934$ & 0.060 \\
\hline Satisfaction with the remuneration package & 0.318 & 1.374 & $1.100-1.716$ & $\mathbf{0 . 0 0 5}$ \\
\hline Satisfaction with the results of the training & 0.339 & 1.403 & $0.945-2.083$ & 0.093 \\
\hline
\end{tabular}

\section{Qualitative interview results}

According to the principle of information saturation, 42 trainees from different departments were selected from the residential training base for qualitative interview. The interview mainly included the degree of consistency between their expectations and requirements during the residency training, the benefits, and disadvantages of participating in the standardized training for residents, and their opinions and suggestions on the current standardized training policies for residents, etc.

After finishing induction, found that the contents of the interview by attending, resident standardization training clinical ability, theory and practice of personnel live in the culture was improved doctor-patient communication skills, but most of the students reflect in the process of living culture, training arrangement, the salary, the teaching consciousness, training content and examination still exist certain problems. Figure 1 shows the detailed results.

\section{Clinical theory and practice ability have been improved}

During live culture, living culture researchers to further consolidate their professional knowledge, accumulated more clinical experience and clinical thinking, professional technical ability and practical operation level are better exercise, had a deeper understanding for the diagnosis and treatment of 
disease, improve the ability of its diagnosis and treatment, to the medical work better for the future laid a solid foundation.

\section{Doctor-patient communication ability has been trained}

Interpersonal communication ability is one of the main contents of standardized training for Resident doctors in China. Through the training in this aspect, residents can listen to patients and family members patiently, and control their own emotional response, their communication skills, cooperation ability, affinity for patients have been improved to varying degrees.

\section{Unreasonable training arrangements.}

First, the department rotation is not scientific. The rotation time in my own department is short, but the rotation time in other departments is long, which cannot fully meet my own key training needs; Second, during the training period, attend too many meetings unrelated to the training content, making the real time for training shrink, affecting the quality and effect of training; Third, it is difficult to work. Because some patients' conditions are more complex, it is difficult for students who have just graduated or still lack work experience to cope with and deal with it in a short time. Fourth, the work intensity is high. Some departments have strict requirements on students who live and train, and arrange them to work night shifts even though they are busy during the day, resulting in excessive work pressure for some students.

\section{Salary and living security need to be improved.}

Some students believe that the medical industry is characterized by high risk and intensity, and the salary and treatment cannot reasonably reflect their own value in the actual training, the income cannot meet the psychological expectation, and the overtime allowance is less, so it is difficult to effectively mobilize their training enthusiasm. In some training bases, students still need to solve the problem of accommodation by themselves, and the high rental fees have caused a certain economic burden to the trainees. Compared with other students of the same age, some students of master's degree programs have to support their families, which leads to greater psychological pressure]

\section{Lack of awareness of teaching}

In addition, due to the lack of incentive mechanism for guiding teachers in the standardized training residents, their teaching enthusiasm is not high. Therefore, some guiding teachers take clinical work as their work focus and have less teaching time for residents. For the consideration of safety and other factors, some teacher "only looking at but not letting go" mode of teaching, cannot give full play to the initiative of students.

\section{The training content and assessment are not fully implemented}

The training requirements in the training manual cannot be fully implemented in the actual training work, the training content is not professional and targeted, doctors in residential training have few opportunities 
to operate professionally, they are often engaged in unskilled simple manual labor, and their professional skills cannot be greatly improved; The process assessment supervision is not strict, there is a phenomenon of "personal affection"; It is impossible to evaluate the level of humanistic knowledge by neglecting the examination of humanistic quality of resident training doctors in the examination of leaving the subject and daily examination

\section{Discussion}

\section{The clinical theory, practical ability and doctor-patient communication ability of trainees are improved}

More than $80 \%$ of trainees believe that participating in training consolidates their theoretical knowledge and improves their clinical practice ability, In the interview, the trainees indicated that through department rotation, case discussion and other ways, clinical practice skills were strengthened, and department lectures, academic conferences and other ways played an important role in the consolidation of theoretical knowledge. According to data from the National Medical Examination Center, the pass rate of the first clinical practice physician qualification examination for trainees attending standardized resident training in 2016 was 83 per cent, nearly 10 percentage points, and 21.8 percentage points higher than those without training in 2019.In 2017-2019, a total of more than 187,000 trainees obtained qualification certificates for standardized resident training through graduation examination [28].Research by Wang JY, $\mathrm{Li} \mathrm{T}$ and Shen $\mathrm{H}$ also found that standardized resident training promoted the improvement of clinical ability of trainees [29-31].72.6\% of the trainees believed that attending the training improved their doctor-patient communication ability. Trainees believe that under the social background of increasingly fierce competition in medical market, strengthening communication with patients and fully respecting patients' right to know and choice can better improve patients' trust in doctors, guide them to actively support and cooperate with medical work, and reduce unnecessary medical disputes. Ye JJ, Wang T and others found that standardized resident training has improved trainees' doctor-patient communication ability to varying degrees [32-33].

\section{The training arrangement is not reasonable, the training department rotation effect is poor}

453 (43.2 percent) trainees expressed dissatisfaction with the timing of the training. On the one hand, during the training period, trainees need to rotate in various departments. When rotating in departments unrelated to their major, some trainees are not enthusiastic about their work, and they are negative about rotating departments. The base management department of standardized resident training needs to formulate a rotation plan for each trainee. However, due to the large number of trainees and departments, it is difficult to formulate a rotation plan that satisfies all departments and trainees. At the same time, some trainees are transferred to other rotation departments when they are not familiar with the work of the current rotation department, and the rotation effect is poor. On the other hand, the working nature of the in the medical and health industry determines the intensity and difficulty of the work of the trainees. 
The trainees must spend most of their time and energy on the work in the hospital, and for self-study, rest and free allocation is squeezed, resulting in great physical and psychological pressure on the trainees. Mu QN's study found that unscientific training arrangements could affect training effectiveness to some extent [34].

\section{The remuneration and living security of the trainees are not met}

605 (71.9 percent) trainees were not satisfied with remuneration during the training period and had the lowest satisfaction in all survey projects. Through the binary logistic regression analysis, it is found that the satisfaction with salary affects its overall satisfaction with the training work. Trainees' income cannot meet their expectations, resulting in psychological unbalance, training enthusiasm cannot be fully mobilized, affecting the effectiveness and quality of standardized training. The trainees surveyed were concentrated between the ages of 28 and 32, playing more roles and responsibilities, considering less family time and low levels of subsistence allowance on the premise of greater intensity of work, resulting in multiple pressures from all levels seriously weakening their enthusiasm for training. Dai XT, Li XT and other scholars have found that the lack of satisfaction of salary will make some trainees have a certain degree of resistance to training [35-38]. In addition, the facilities, equipment, accommodation, transportation and other security of residential training units are limited, which cannot meet the needs of trainees, and also affects their enthusiasm for training. Huang T and Qi DF believed that if the basic living conditions of the trainees were not guaranteed during the training, they would seriously affect their enthusiasm, initiative, focus, and thus lead to the training quality failing to reach the expectation [39-40].

\section{Teachers in residential training units lack awareness of teaching}

On the one hand, the teacher "only looking at but not letting go", the teacher neglects the clinical practice training of the trainees, cannot 'let go' let the trainees get full exercise, the clinical thinking and post competency of the trainees are insufficient. On the other hand, a small number of teachers do not attach importance to the quality and level of teaching work in ideology, and only arrange repetitive work such as writing medical records and dressing change for trainees. They seldom give targeted guidance to students in professional knowledge and lack communication with trainees, which makes it difficult for trainees to improve their ability substantially. In the base evaluation work, it is found that there is no exit and incentive mechanism for the selection and evaluation of standardized resident training teachers. In the absence of incentive mechanism in the teaching work of residents, at the same time, due to the busy clinical work, high pressure, and undertake other levels of teaching tasks, complete personal scientific research, promotion needs and other 'complicated' work, some teachers are not enthusiastic about teaching work. Ji HL and Gong $\mathrm{Y}$ et al. also found that the lack of incentive policies made teachers not enthusiastic enough about clinical teaching, and believed that due rewards were not paid, resulting in the low enthusiasm of some teachers in teaching [41-42]. Wen L and Su FW et al. found that teachers, as clinicians, need to go to the front line of clinical work, receive and see doctors every day, and work is very 
busy. In the long run, there will be conflicts between clinical work and teaching tasks, so that clinicians with heavy clinical work will increase the additional workload [43-45].

\section{The training content and assessment work are not in place}

$35.3 \%$ of the trainees were not satisfied with the training content, and binary logistic regression analysis showed that the satisfaction with the training content affected their overall satisfaction with the training work. In the actual implementation of the training work, some residential training units ignored the training content required in the specification training manual, making some important training impossible to be fully implemented. According to the survey of Chang SY and Wei YN et al., although some units in the residential training involve the content of professional theoretical knowledge, they are far from meeting the actual needs of students, and their professional ability cannot be greatly improved [46-47]. In terms of assessment, there is a lack of specialized assessment regulatory agencies and oversight mechanisms involved: Due to different specialties involve different sub-specialty rotations, the assessment process, assessment stage and assessment content are not the same. The management department can only determine whether the assessment goal is achieved according to the materials provided by the department, and it is difficult to establish a timely and effective supervision mechanism. Medical humanistic quality is one of the important contents of standardized resident training. It is a compulsory course for trainees to embark on clinical work. It is an important pillar for the full realization of healthy China and helps to cultivate and improve the professional quality of physicians. However, the assessment of humanistic quality is ignored in the assessment indicators. At the same time, Yao L's research found that there was a lack of specialized assessment supervision institutions and supervision mechanisms in standardized resident training. It also ignores the assessment of medical ethics, doctorpatient communication, professional ethics, and other humanistic qualities [48].

\section{Suggestions}

\section{Arranging resident training time reasonable and improving resident training efficiency}

Reasonable curriculum system can be set up through self-study, video lectures, distance learning in various forms; effective design department rotation planning, combined with the needs of trainees, reasonable arrangements for trainees rotation time; adjustments to rotation arrangements based on the actual situation, particularly for married or child-bearing trainees; the competent department of resident training should formulate a clear reward and punishment system and enhance the responsibility consciousness of relevant personnel, so as to ensure the smooth development of the training work and ensure the effective rotation work.

\section{Improving trainees' salary and guaranteeing their living standard}


The government should increase financial support and coordinate the establishment of special funds by resident personnel units, training bases and other relevant departments; formulate capital management and use methods to improve capital use efficiency[49]; establish a sound training scholarship system, quantify scores according to established standards, regularly select excellent residents to encourage scholarships, effectively improve the life treatment of residents during training and enhance the enthusiasm of residents[50]. To meet the reasonable needs of trainees in accommodation and transportation as much as possible, and provide reliable material and spiritual guarantee for better training.

\section{Raising the awareness of teachers' responsibility and improving teaching quality}

The base should train full-time teaching teachers, update the list of teachers in time, bring qualified personnel into the teaching team, reduce the pressure to complete clinical work and consider the teaching, promote teachers to focus on residential training and teaching, strengthen the incentive and restraint mechanism of teaching. In "Standard for standardized resident training bases (revised 2020)" [50], the specific requirements of incentive and exit of teacher selection training evaluation are put forward, and the training task and teaching quality are taken as important indicators to guide the performance of physicians, evaluate the priority and promote the professional title, and are included in the overall evaluation system of the hospital. Strengthen the interaction between teachers and trainees, trainees should regularly report to teachers learning, timely detection of problems, to ensure the pertinence, effectiveness, and professionalism of the guidance work [51].

\section{Strengthening the implementation of training content and improving the assessment system}

The training base should strengthen the implementation of relevant policies, develop reasonable training case that meet the needs of the trainees, develop personalized training case for different levels of trainees, avoid "one size fits all", teach trainees in accordance with their aptitude, and truly meet the learning and growth needs of different levels of trainees [52-53]. The training base should improve and perfect the standardized training and assessment system of residents, establish a unified standard, scientific and reasonable assessment content, make the assessment index as objective as possible [54], and strengthen the supervision and supervision of daily assessment, department assessment and other process assessment, improve the objectivity and impartiality of assessment work, and put an end to the "human relationship score". The establishment of humanistic care mechanism and the creation of an overall medical humanistic education environment can properly add the humanistic practice skill examination to the standardized training and assessment project of residents [55-56], actively penetrate humanistic care and guide the conscious improvement of humanistic quality of residents [57-58].

\section{Conclusions}


The standardized resident training system in China is the Breakthrough and Key Link of the China's New Medical Reform. The government tries to align the international standards through the standardized reform of resident training, to improve the health service level of medical institutions in China, narrow the gap between different medical institutions, and achieve the goal of equalization of public health services. The Standardized resident training system plays an important role in improving doctors' clinical ability and doctor-patient communication skills. However, with the gradual progress and deepening of the work, many problems have been found in the survey, such as unreasonable training arrangements, low salary and living security level, insufficient awareness of teachers' responsibility, and imperfect training content and evaluation system.

\section{Research Limitations}

This review is based on the development process and practice of standardized resident training system in China, focusing on the main aspects of China's standardized resident training system, the problems existing in policy practice and possible countermeasures and solutions. But since the standardized resident training involves different specialties such as clinical medicine, stomatology, traditional Chinese medicine, and integrated traditional Chinese and western medicine, as well as trainees of different natures such as parallel master's degree, socialized trainees, and commissioned doctors. This paper did not conduct in-depth research on the nature of specific majors and trainees, and the countermeasures and suggestions of different majors and trainees in standardized training practice have certain limitations.

\section{Declarations}

\section{Acknowledgements}

We appreciate all the authors for valuable comments and suggestions provided when discussing this study. All statements are solely those of the authors and do not necessarily reflect the views of their employers or grant-making agencies.

\section{Funding}

National Natural Science Foundation of China囚71804130囚; Shandong Province Education Science "13th Five-Year Plan" Project (YC2017091区

\section{Availability of data and materials}

The data used for this manuscript from National government website and issued by the relevant policy documents.

\section{Authors' contributions}


ZL, SL, WM, and QY conceptualized the study and analyzed the data. ZL, SL, and WM wrote the first draft of the manuscript together, WY, ZC, DM, SJ, HP and JS commented on the manuscript critically. All authors read and approved the final manuscript.

\section{Authors' information}

All the authors are from Management School of Weifang Medical University except JS is from Weifang Hospital of Traditional Chinese Medicine. QY is the professor whose research interests are health policy and health economic evaluation. WY is the professor whose research interest is health care management. $\mathrm{ZC}$ is the associate professor whose research interest is social medicine. DM is a lecturer whose research interests are health emergency management and health economics. ZL, SL, WM, SJ and HP are graduate students majoring in social medicine and health service management. JS is a lecturer whose work is management of standardized resident training program.

\section{Competing interests}

The authors declare that they have no competing interests.

\section{Consent for publication}

Not applicable.

\section{Ethics approval and consent to participate}

No ethical approval required for this study.

\section{References}

1. The Chinese government website. Guidance on establishing standardized resident training system. http://www.gov.cn/gzdt/2014-01/17/content 2569096.htm.

2. Meng Q. Research on the establishment of specialist training and access system in China [M]. China Union Medical University Press, 2008:4.

3. Xing LY, Wang C, Qi XJ, et al. Postgraduate medical education systems overseas and their Inspirations. Chinese Journal of Hospital Administration, 2015,31 (12): 884-887.

4. Huddle T S, Heudebert G R. Internal medicine training in the 21 st century. Academic Medicine, 2008, 83(10):910-915.

5. Cooke M, Irby D M, Sullivan W, et al. American medical education 100 years after the Flexner report. New England Journal of Medicine, 2006, 355(13):1339-1344.

6. RCPSC. RCPSC Introduction [EB/OL]. (1998-08-16) [2012-02-07] http://www.royalcollege.ca/public/about.

7. Freiman A, Natsheh A, Barankin B, et al. Dermatology postgraduate training in Canada: CanMEDS competencies[J]. Dermatol Online J, 2006, 12(1):6. 
8. Liu P, Geng Y, Wu XL, et al. Enlightenment of competency-oriented Canadian resident training framework on Chinese traditional medicine resident training system. Journal of Traditional Chinese Medicine Management, 2017, 25(20):7-9.

9. Zhang HJ, Zhang WD. Reflection and enlightenment on the training mode of resident doctors in foreign countries. Journal of Chengde Medical University, 2017, 34(02):179-180.

10. McGowan, A. Modernising medical careers: educational implications for the emergency department. Emergency Medicine Journal, 2006, 23(8):644-646.

11. Postgraduate medical education and training board. Standards for curricula and assessment systems [M]. London: PMETB, 2008.

12. Nasca TJ, Philibert I, Brigham T. eds. The Next GME Accreditation System-Rationale and Benefits. N ENCL J MED, 2012, 366(): 1051-1056.

13. GMC. The Trainee Doctor [EB/OL]. 2010 [2013-03-14]. http://www.gmcuk.org/Trainee_Doctor.pdf_39274940.pdf.

14. ACGME. BYLAWS [EB/OL]. 2011 [2013-03-14]. http://www.acgme.org/ acgmeweb/Portals/0/ab_ACGMEbylaws.pdf.

15. WFME. Global standards for post-graduate medical education [M]. Copenhagen 2003.

16. Swing SR, Clyman SG, Holmboe ES, eds. Advancing Resident Assessment in Graduate Medical Education. Journal of Graduate Medical Education, 2009:278-286.

17. GMC. Standards for curricula and assessment systems [EB/OL].2010 [2013-03-14]. http://www.gmcuk.org/Standards_for_curricula_and_assessment_systems_0410.pdf_48904896.pdf

18. Wang $H$, Xie $T, X u T$, et al. Inspiration on American Residency Training System. Hospital Administration Journal of Chinese People's Liberation Army, 2011, 18(9):899-900.

19. Meng K, Zhang L. Comparative study of the clinician training system between China and Japan. Chinese Journal of Hospital Administration, 2009(10)717-720.

20. Li XX. Implementation status and effect evaluation of resident standardized training system in Sichuan province[D]. Southwest Jiaotong University, 2018.

21. Opinions of the General Office of the State Council on Deepening the Reform of Medical and Health System. Available online: http://www.gov.cn/test/2009-04/08/content_1280069.htm(accessed on 7 APR 2021).

22. Guidance on Establishing a Standardized Resident Training System. Available online: http://www.gov.cn/gzdt/2014-01/17/content_2569096.htm (accessed on 7 APR 2021).

23. Methods for the Management of Standardized Resident Training (trial). Available online: http://www.nhc.gov.cn/qjjys/s3593/201408/e810bec360b64994bfc5b60273b0fa28.shtml (accessed on 7 APR 2021).

24. Standard for Accreditation of Standardized Resident Training Base (Trial). Available online: http://www.nhc.gov.cn/qjjys/s3593/201408/946b17f463fa4e5dbcfb4f7c68834c41.shtml (accessed on 7 APR 2021). 
25. Contents and Standards of Standardized Resident Training (Trial).Available online:

http://www.nhc.gov.cn/qjjys/s3593/201408/946b17f463fa4e5dbcfb4f7c68834c41.shtml (accessed on 7 APR 2021).

26. Implementation Methods of Recruitment for Standardized Resident Training. Available online: http://www.nhc.gov.cn/qjjys/s3593/201510/e9edb9ed82224b28bc935188f9f1ff38.shtml (accessed on 7 APR 2021).

27. Implementation Methods of Standardized Resident Training Assessment. Available online: http://www.nhc.gov.cn/qjjys/s3593/201510/e9edb9ed82224b28bc935188f9f1ff38.shtml (accessed on 7 APR 2021).

28. Letter Concerning Reply to Proposal No. 3340 (495 for Medical Sports) of the Third Session of the Thirteenth National Committee of CPPCC. Available online: http://www.nhc.gov.cn/wjw/tia/202101/43562a31593f4401b15db156d8c1726d.shtml

29. Wang JY. A survey on the cognition and attitude of standardized training physicians and students towards standardized training for resident physicians in Shanghai [D]. Fudan University,2012.

30. Li T. Evaluation on the implementation effect of standardized training for resident physicians [D]. North China University of Science and Technology,2020.

31. Shen H. Study on the evaluation of standardized resident training of a Grade A Tertiary Hospital in Guangzhou [D]. Southern Medical University, 2017.

32. Ye JJ. Study on the effect of standardized training system for resident physicians in Fujian Province [D]. Fujian Medical University,2016.

33. Wang T. Research on evaluation of standardized training effect of resident doctors in Xinjiang region [D]. Xinjiang Medical University,2015.

34. Mu QN. Research on the implementation of standardized training system for resident physicians in a Hospital of Shandong Province [D]. Shandong University,2021.

35. Dai XT. Problems and countermeasures of standardized resident training based on satisfaction survey[D]. Nanjing Medical University, 2017.

36. Li XT. Problems and countermeasures in standardized residency training. Health Vocational Education, 2017, 35(08):148-149.

37. Guo HY, Gu BB, Zhang XQ, et al. Problems in standardized training for resident doctors and solutions. Modern Hospital Management, 2015, 13(04):10-12.

38. Li FY, Wen Y, Lei PG, et al. Current situation of standardized training for resident doctors in China. China Continuing Medical Education, 2019, 11(35):92-94.

39. Huang T, Wang WT, Li Y, et al. Problems and countermeasures of standardized residency training. Journal of Medical Information, 2019, 32(04):19-20.

40. Qi DF. Analysis and countermeasures of standardized training for resident doctors. Academic Journal of Guangzhou Medical University, 2017, 45(04):77-79. 
41. Ji HL, Li JM, Zhang XW. Innovative exploration of the problems in standardized training of resident doctors. Modern Hospital Management, 2017, 15(05):27-29.

42. Gong Y. Quality analysis and countermeasures of standardized training for residents in Sichuan Province[D]. Southwest Jiaotong University, 2013.

43. Wen L, Zhao HP, Liu R. Problems and countermeasures of standardized training for resident doctors. Journal of Inner Mongolia Medical University, 2015, 37(S2):273-275.

44. Su FW, Zheng YQ, Shi J, et al. Research on the status quo of standardized residency training rotation plans and curriculum settings. Chinese Journal of Graduate Medical Education, 2019, 3(01):79-83.

45. Qi M, Chen HJ, Wei XZ, et al. Analysis and prospect of standardized residency training in China. China Higher Medical Education, 2013(04):7-8.

46. Chang SY. Investigation on the construction of standardized training base for residents in Xinjiang[D]. Xinjiang Medical University, 2016.

47. Wei YN. Investigation on the construction of standardized training base for resident doctors in Guangxi[D]. Guangxi Medical University,2017.

48. Yao L, Zeng MR, Li H, et al. Current situation and countermeasures of standardized training for resident doctors in China. Hainan Medical Journal, 2018, 29(11):1612-1614.

49. Zhao YW, Wang $Y$, Chen $X L$, et al. Analysis on the problems of standardized training of residents in China and countermeasures. Health Economics Research, 2019, 36(3):12-14.

50. Notice on soliciting opinions on content and Standard of Standardized Resident Training (2020 Revision) and Standard of Standardized Resident Training Base (2020 Revision) Available online: https://www.ccgme-cmda.cn/news/12226/article (accessed on 14 APR 2021).

51. Gang J. Current status and prospect of teaching staff construction on resident's standardized training. China Modern Doctors, 2016,54 (21): 148-151.

52. Xu H, Yang GB, Yi XM. Reflections on standardized training of resident doctors. Journal of Medical Postgraduates, 2010, 23(8):865-867.

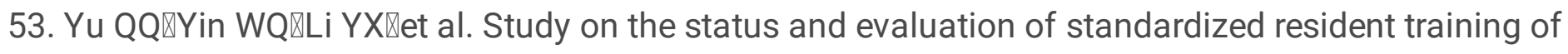
entrusted training doctors based on Kirk-Patrick Model. The Chinese Health Service Management, 2019, 36(9):689-692.

54. Liu D. Effect of standardized training for resident doctors in Jilin province[D]. Jilin University, 2016.

55. Li QY, Xiao LH, Liu HL, et al. Analysis and reflection on the current standardized training for resident physicians. Chinese Health Service Management, 2016, 33(05):374-376.

56. Gao XY, Sha EW, Lin HX, et al. Discussion on current situation of standardized residency training. Journal of Qiqihar Medical University, 2015, (2):258-259.

57. Di TN, Ge CL. The current situation and thinking of resident standardized training. Continuing Medical Education, 2020, 34(3):12-14.

58. Liu J, Yin JQ, Fang ZS. Analysis and countermeasures of standardized training for resident doctors. Renowned Doctor, 2018(11):239+241. 
Figures

The training arrangement is not reasonable
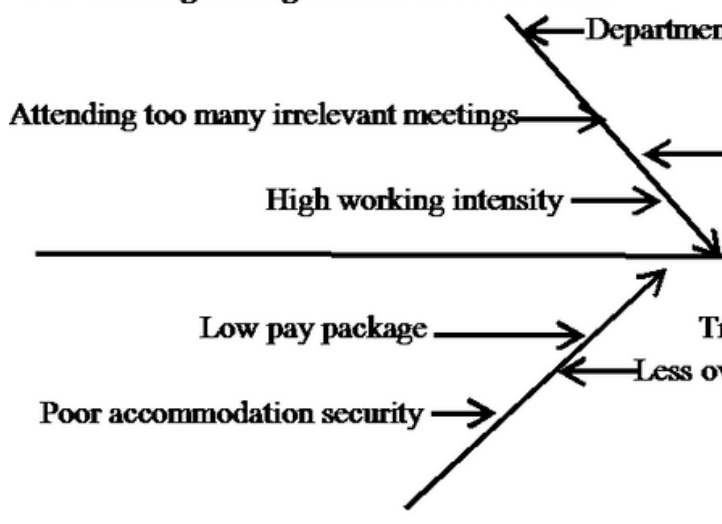

The level of treatment and security is low
Lack of awareness of teaching

$\mathbf{Y}$ "only looking at but not letting go"Difficult work

Training manual requirements cannot be fulfilled Lax assessment and supervision $\rightarrow$

-Ignore the appraisal of the humanities

\section{Figure 1}

fishbone diagram analysis of problems in training from the perspective of residents

\section{Supplementary Files}

This is a list of supplementary files associated with this preprint. Click to download.

- revisonnote.docx 